\title{
Morphology of basal crevasses at the grounding zone of Whillans Ice Stream, West Antarctica
}

\author{
Robert W. JACOBEL, Knut CHRISTIANSON, ${ }^{*}$ Adam C. WOOD, Kevin J. DALLASANTA, \\ Rebecca M. GOBEL
}

Physics Department, St Olaf College, Northfield, MN, USA

E-mail: jacobel@stolaf.edu

\begin{abstract}
The transition from limited-slip conditions at the base of grounded ice to free-slip conditions beneath floating ice occurs across the few-kilometers-wide grounding zone. This region involves either an elastic flexural transition from bedrock to hydrostatically supported elevations (often tidally influenced), a transition from thicker to thinner ice over a flat bed, or some combination of these two processes. In either case, ice must flow across a changing stress field, often resulting in brittle deformation, manifested as basal crevassing. Thus the position and morphology of basal crevasses reveal important information about the stress state across this transition. Our gridded ground-based radar surveys on Whillans Ice Stream, West Antarctica, indicate a complex pattern of basal crevasses, but most are associated with regions where the surface elevation gradient is steepest. Due to the high reflectivity of sea water, we image many off-nadir crevasses from a corner-reflector geometry involving reflections from the ice/sea-water interface and then from the crevasse, producing echoes with an inverted phase that could be misinterpreted as subglacial returns. Our results indicate that basal crevasses offer a rich dataset for diagnosing stress state and salient processes across grounding zones, and that special care is needed when interpreting subglacial returns in radar data.
\end{abstract}

KEYWORDS: Antarctic glaciology, crevasses, glacier geophysics, ice/ocean interactions, radio-echo sounding

\section{INTRODUCTION}

The grounding zone is an extended triple junction between overlying ice, bed and the ocean. Processes in grounding zones are critical to ice-sheet mass balance because they determine mass flux from grounded to floating ice, and thus eventually to the ocean. In addition to direct interactions at the ice/ocean interface (e.g. ocean-driven basal melt or basal ice accretion) interactions between basal hydrology, tidal processes and sediment flux at the ice-sheet bed influence grounding-line position and stability (Catania and others, 2010). Initial, primarily remote-sensing-based studies focused solely on locating the tidally influenced grounding zone and have achieved considerable success, with continental-scale mapping of grounding zones now being possible (Fricker and others, 2009; Brunt and others, 2010; Rignot and others, 2011a). Although inferences of basal processes from remote-sensing studies are possible and useful, direct observations of grounding-zone basal processes are needed to allow accurate ice-sheet modeling and understanding (Alley and others, 2007; Anandakrishnan and others, 2007; MacGregor and others, 2011). Despite only covering limited areas, radio-echo sounding (RES) and active-source seismic surveys have provided direct evidence of subglacial sedimentation and complex estuarine interactions between ice-sheet basal hydrology and the ocean (Christianson and others, 2013; Horgan and others, 2013a,b; Parizek and others, 2013). Most previous radar

*Present address: Courant Institute of Mathematical Sciences, New York University, NY, USA studies focused on basal reflectivity or internal stratigraphy. In this study, we discuss the radar depiction of basal crevasses and use basal crevasses to study grounding-zone features. Basal crevasses are often formed beneath ice shelves, where they are typically produced as the ice goes afloat at grounding zones (e.g. Bindschadler and others, 2011), in response to longitudinal stress gradients, such as those formed in association with surface crevasses as the floating ice accelerates (e.g. Luckman and others, 2012; McGrath and others, 2012), or in connection with basal melt channels (e.g. Vaughan and others, 2012). In other locations, relict basal crevasses have been used to infer the location of former grounding zones or regions of past high basal shear stress (e.g. Jacobel and others, 2000; Catania and others, 2006; Matsuoka and others, 2009). The theory of crevasse formation at the bottom of an ice shelf was developed by Jezek (1984), who used it to infer the magnitude of buttressing forces on the Ross Ice Shelf. Vaughan and others (2012) developed a finite-element model to explain the occurrence of basal crevasses at the apices of subglacial melt channels. The common theme in all of these studies is that the location and morphology of basal crevasses reveal important information about the changing stress state of ice as it flows or transitions from a grounded to a floating regime.

In this study, we imaged a large number of basal crevasse signatures in radar data acquired at the Whillans Ice Stream grounding zone (WGZ), West Antarctica (Fig. 1). We first discuss the occurrence and location of these basal crevasse features in the context of the ice dynamics in the WGZ region. We then discuss the specific features of how these crevasses are imaged in our radar data. 


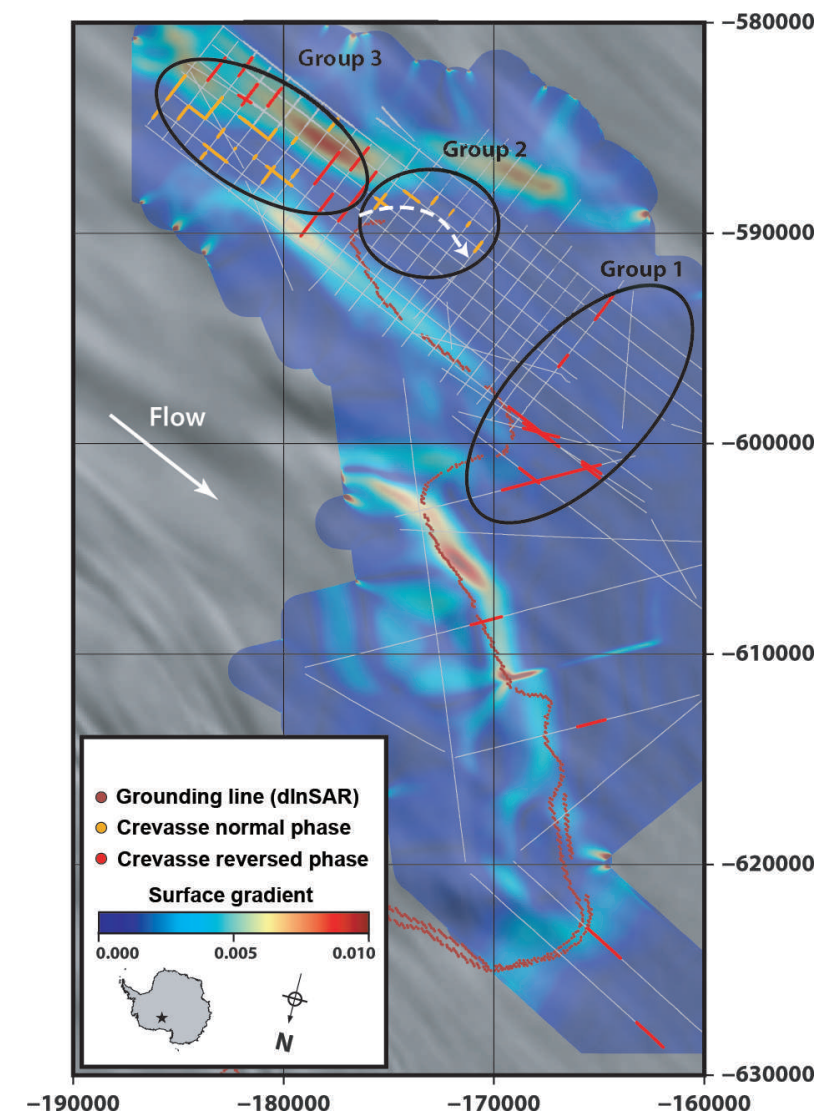

Fig. 1. Map of the Whillans Ice Stream grounding zone, showing crevasse signature locations along the radar gridlines (white). The magnitude of the gradient of surface elevation obtained from GPS measurements along the radar lines is shown in color. The grounding line predicted from dInSAR tidal flexure measurements is shown for comparison (brown). The grounded peninsula region discussed in the text is toward the bottom of the figure; the embayment is toward the top, where the grid spacing is regular. Crevasses are clustered into three groups for the discussion. Those showing reversed echo phase are depicted in red, normal phase in orange. Approximate location of the subglacial channel discussed in the text is shown as a white dashed line. Background is Moderate Resoution Imaging Spectroradiometer (MODIS) imagery; coordinates are South Polar Stereographic.

\section{GLACIOLOGICAL ENVIRONMENT AND BASAL CREVASSE LOCATIONS}

\section{Field site}

The high velocities of the Siple Coast ice streams, despite low driving stresses, are the result of dilatant till at the bed, that reduces basal drag and allows sliding (Alley and others, 1987; Blankenship and others, 1987). Recently a network of active subglacial lakes (Fricker and others, 2007; Fricker and Scambos, 2009) has been discovered under Whillans Ice Stream. These lakes are connected by channels that fill and drain on timescales of months to years. Their role in the transport of sediment and water under the ice stream is not well understood. The Whillans Ice Stream Subglacial Access Research Drilling (WISSARD) project was designed to investigate one of these lakes, Subglacial Lake Whillans and its possible hydrologic connection to the ocean at the Whillans grounding zone, using geophysical surveys and subglacial access drilling (Christianson and others, 2012; Horgan and others, 2012).
Over 650 line-kilometers of gridded kinematic GPS and impulse radar data at a center frequency of $5 \mathrm{MHz}$ (Welch and Jacobel, 2003; Welch and others, 2009; Christianson and others, 2012) were collected as part of the surface geophysics study of the WGZ in the austral summer 2011/12 field season (Fig. 1). Radar processing included bandpass filtering, correction for antenna spacing, interpolation to standard trace spacing and two-dimensional (2-D) migration. Approximately 50 line-kilometers of active-source seismic reflection data were also acquired (Horgan and others, 2013a,b). These studies focused on two areas of the WGZ, one over a subglacial peninsula where the transition to flotation is abrupt (lower part of Fig. 1; Christianson and others, 2013) and the second over a subglacial embayment where several dynamic subglacial lakes drain to the ocean (upper part of Fig. 1; Carter and Fricker, 2012), likely resulting in episodic high sediment and water flux across the grounding line. Results from the seismic and radar studies show that the embayment is an estuary (Horgan and others, 2013a), consisting of a hydropotential low upstream of the grounding zone linked to the ocean by a hydropotential trough and a large subglacial channel (upper left and central portion of the grid in Fig. 1). This subglacial channel has an apparent width of $\sim 1 \mathrm{~km}$ and a maximum depth of $7 \mathrm{~m}$. The hydropotential trough continues upstream of the grounding zone and results from an alongflow depression in surface elevations. Pressure differences along the trough axis are within a range that can be overcome by tidally induced processes, making the interaction of subglacial and ocean water likely. The ocean water column imaged within the embayment is everywhere $<12 \mathrm{~m}$ thick, implying that the estuary is well mixed by tidal processes.

\section{Crevasse location}

Figure 1 shows the locations of basal crevasses imaged by RES in our survey. The inlandmost grounding line identified using differential interferometric synthetic aperture radar (dlnSAR) is also shown (Rignot and others, 2011b). At first glance, crevasses appear to correlate roughly with this grounding line, but closer inspection reveals that many locations along the grounding line crossed by our survey do not show basal crevasses; elsewhere in our grid we find crevasses both downstream and upstream of the dInSAR grounding line. For the purposes of discussion we define three groupings that encompass most of the crevasses, as labeled in Figure 1: (1) a group along the geographic north side of the embayment just after the ice comes afloat; (2) a closely spaced group on the opposite side of the embayment and somewhat upflow, where grounding is not defined by dInSAR, and (3) a group at the head of the embayment at the upstream end of the survey grid.

Using GPS surface elevations collected along RES profiles, we mapped the gradient of surface topography to identify the areas of steepest slope (colors in Fig. 1). Given that the thickness is nearly constant, these zones produce the largest gravitational driving stress. Just downstream, where the ice comes afloat, basal drag goes to zero and the ice experiences high longitudinal stress gradients. Thus, locations just downstream of these steep surface slopes are where crevassing would be expected. In several places (e.g. some of the crevasses within group 1) the steepest slopes correspond well with the grounding line depicted by dInSAR as the inland limit of tidal flexure, but in others they do not. This is likely due to complex topographic or hydrological influences on ice-sheet dynamics, that may be relatively 

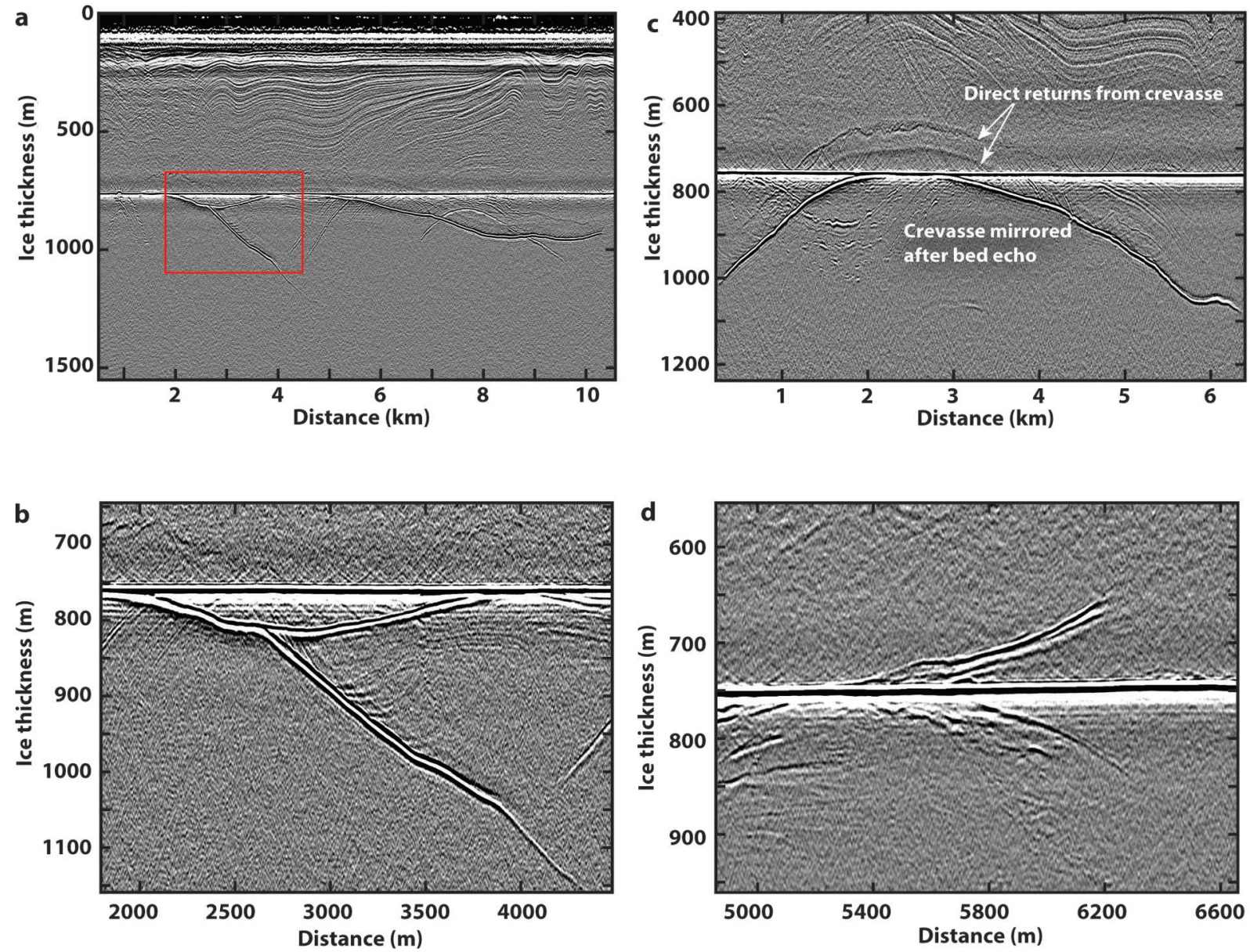

Fig. 2. Off-nadir returns from crevasses along the embayment grid. (a) Four crevasses in group 1 from Figure 1 with detail (box) shown in (b). Note the phase reversal of the crevasse echoes relative to the basal reflector. (c) Detail of another crevasse from group 1, showing a strong off-nadir echo mirrored via a basal reflection. Two additional sets of echoes from the same feature also arrive at shorter times in a direct return with the same phase as the basal reflector (geometry shown in the schematic diagram, Fig. 3). (d) Close view of one of the crevasse pairs marking the water-filled channel in group 2. The near-symmetry at both shorter and longer return times than the basal reflector results from imaging both sides of the feature simultaneously as the radar passes over the channel.

inactive on tidal timescales and thus not easily detectable by dInSAR. However, there is generally a correlation between areas of steepest surface slope and the location of basal crevasses immediately downstream, as expected. Moreover, in areas where basal crevasses occur prior to ungrounding, they are associated with the downstream side of high surface slopes, suggesting their formation is associated with high longitudinal stresses. Although tidal strain cracking is occasionally evident at the surface, the lack of extensive surface crevassing suggests that the stress change occurs at the ice-sheet bed, consistent with a transition from a limited (or no-slip) to a free-slip basal boundary. Thus the position of basal crevasses reveals important information about the stress state at the ice/bed interface.

\section{DEPICTION OF CREVASSES BY RADAR}

Figure 2 shows four RES profiles depicting basal crevasses. Two features of our radar system are relevant to the way crevasses appear in these profiles. First, the antenna beam pattern of the low-frequency dipole antennas oriented endto-end at the air/firn interface has strong lobes to either side of the travel path and also both fore and aft of the radar transmitter and receiver (Arcone, 1995). This means that returns from off-nadir can be as strong as or even stronger than those from directly below the radar. Second, the radargrams do not depict crevasse geometry realistically, but rather show the pattern of reflected and scattered energy from the crevasse projected onto the nadir plane as the radar moves along the surface. Radar profiles tend to depict basal topography and folded internal stratigraphy with relatively accurate proportions, and slopes, only because the geometry of these structures is generally more 2-D and of a much greater spatial scale than the radar wavelength $(\sim 32 \mathrm{~m}$ for $5 \mathrm{MHz}$ in ice). At the other end of the size spectrum, point diffractors are also easily interpreted in RES profiles. In contrast, crevasses are three-dimensional objects, often complex in shape, and their dimensions are on the same order as the wavelength of radar waves in ice. These differences make interpretation of the crevasse returns more difficult, even when objects can be imaged from more than one perspective in gridded data. Most of what produces the crevasse signature in the profile is the changing location of the radar relative to the crevasse. This 'moveout', due to the changing separation, turns point reflectors into hyperbolae and line reflectors into more complex line shapes.

One very useful feature of impulse radar is that phase information is directly recorded in the radargram. Radar waves in ice that reflect from bedrock, sediment or water have an inverted phase relative to the transmitted wave 


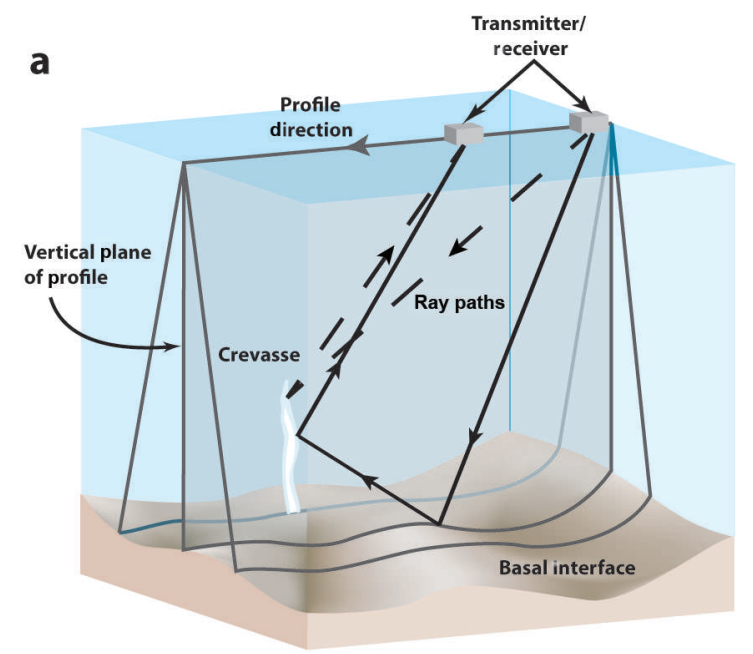

b

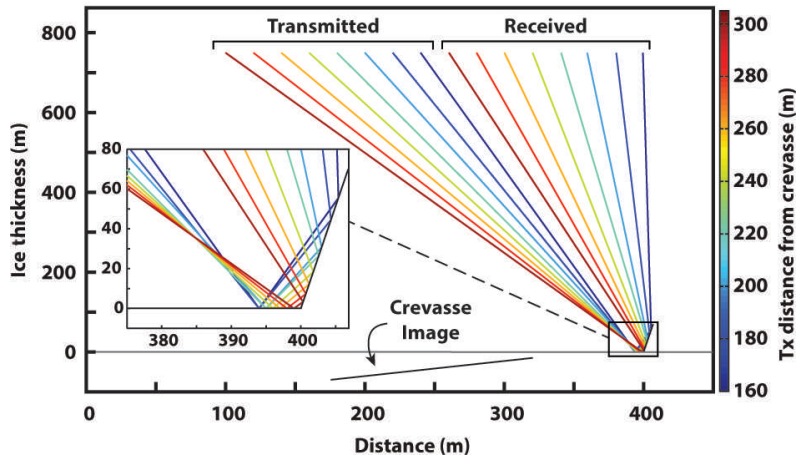

Fig. 3. (a) Schematic diagram showing the reflection geometry for energy returned from an off-nadir crevasse via two paths, one direct (dashed line) and the other involving a reflection from a bright basal interface (solid line). (b) Modeled ray paths from transmitter to receiver for a corner reflector consisting of a basal reflection followed by reflection from a water-filled crevasse. Each color corresponds to an allowed path; the time/distance of the reflection is depicted relative to the nadir basal arrival. The locus of these points is a crevasse signature from 'below' the basal interface. Inset detail shows that points higher on the crevasse are illuminated as the radar approaches.

because of the higher dielectric constant of these media (Peters and others, 2005). In all the profiles in this study, the ice/bed interface echo is seen as a white-black-white Ricker wavelet. In contrast, echoes from approximately half of the crevasses we detected (e.g. Fig. 2a-c, but not d), have the reverse of this phase (black-white-black). Any explanation of the crevasse reflection mechanism must account for this reversal. The spatial pattern of crevasses with reversed phase is shown in red in Figure 1.

The appearance of these echoes arising from below the ice/bed interface is almost always an illusion because of the longer travel time for any echo other than the direct nadir reflection. If the waves were actually reflected from within the basal substrate, the only possibility for the observed phase reversal relative to the bed echo is that these waves reflected from a deeper interface with a lower dielectric value than the basal substrate. We reject this hypothesis for several reasons. The attenuation of radar waves in sea water is very large (the loss tangent is 11.4 ) and energy is dissipated in $<1 \mathrm{~m}$. A similar argument about attenuation can be made for a sediment substrate, but possible combinations producing the correct phase do exist (e.g. a layer of wet sediment underlain by hard bedrock). In our case, the complex geometry of the reflections, their apparent dips at odd angles in different directions, and their intersections in some locations (e.g. Fig. 2b) give us certainty that these are not reflections from targets below the basal interface.

We argue instead that the reversed phase echo we observe from these crevasses is produced by an effective corner-reflector, two reflective planes that intersect at close to $90^{\circ}$ (Fig. 3a). In this geometry, a ray first reflects with little loss in power from the nearly planar ice/water interface, is subsequently scattered or reflected from a near-vertical crevasse wall and then returns to the receiver (Fig. 3a). Two reflections from water (a medium with higher dielectric value than ice) produce a non-inverted phase on the return. This hypothesis is supported by two lines of evidence relating to the power and the geometry of a double reflection. First, we find that the power returned from offnadir crevasses (like those in Fig. 2a-c) is, on average, reduced by only $11 \mathrm{~dB}$ relative to the ice/water basal echo. They are very bright reflectors. A specular reflection from water at near-normal incidence produces a loss of less than $\sim 2 \mathrm{~dB}$; thus there is much energy returned into the ice after a single reflection from a near-planar surface. Subsequent reflection (or scattering) from a crevasse at a lower incidence angle reduces the power by up to an additional $10 \mathrm{~dB}$ at angles approaching $70^{\circ}$. With additional attenuation due to the slightly longer travel path relative to the nadir bed echo, these losses give a good match to the values we observe.

Second, we modeled ray-path geometries for a corner reflector consisting of an ice/water specular reflection followed by a specular reflection from a near-vertical crevasse tilted a few degrees away from the radar, and we find that they agree well with our observations. Double reflections connecting the transmitter and receiver with their $160 \mathrm{~m}$ separation are constrained in this geometry over a range of receiver distances from $\sim 240 \mathrm{~m}$ away from the crevasse until the receiver is directly above the crevasse, similar to our observations (Fig. 3b). As the radar approaches the crevasse, energy is returned in this geometry from points higher along the crevasse wall, leading to shorter travel times that approach the nadir arrival. This pattern gives the appearance of a sub-basal reflector, which is clearly not the case. We note that the process can also work in reverse, i.e. the transmitter and receiver positions can be reversed so that the reflection first occurs off the crevasse and then the bottom. Thus a profile run in the opposite direction will produce approximately the same signature. In contrast, the system can 'see' a crevasse only from one side; once past the nadir it can no longer return energy along that path. We also note that the constraint on the distance to the crevasse just discussed need not be along the direct travel path of the radar. Reflections from one side or the other will produce the same kinds of crevasse signatures as the radar moves, with the component of the separation projected along the travel path at the nadir. If the crevasse eventually intersects the radar travel path, its apparent depth will be the same as the basal echo.

In some circumstances a crevasse may be imaged by the corner-reflector geometry just discussed and simultaneously imaged by energy scattered directly from the crevasse back to the receiver (i.e. with no basal reflection). In this case, returns from the upper portion of the crevasse arrive at shorter travel times than the basal echo. This is seen (Fig. 2c) as a weaker non-specular echo with the expected phase the same as the bed echo. 


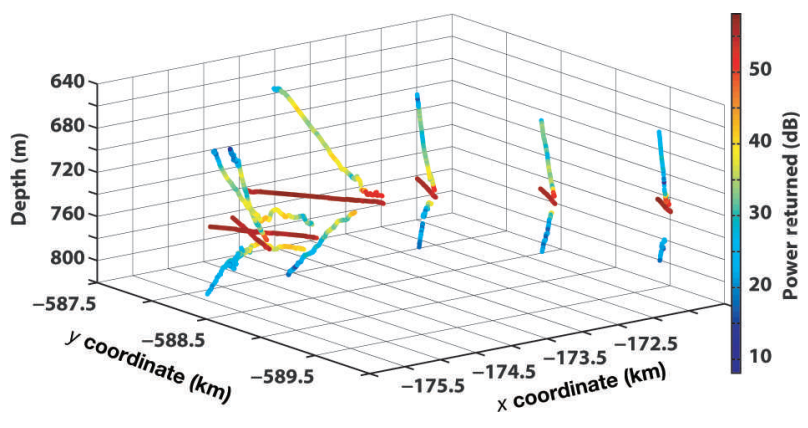

Fig. 4. Three-dimensional depiction of the location of the six 'mirrored' crevasses in group 2 (Fig. 1). Color is the returned power for both branches of the crevasse signature and the basal echo. The locations of these crevasses closely match a water-filled channel seen in the seismic profiles. The crevasse depicted in the radar profile, Figure $2 \mathrm{~d}$, is the third from the right seen in perspective here.

The locations of the crevasses displaying a reversed phase echo generally occur where the ice is afloat (e.g. group 1), together with the crevasses seaward of grounding in the lower portion of Figure 1. The existence of a highly reflective bed interface likely enhances the occurrence of this echo mechanism, though crevasses with reversed phase can also be seen in parts of group 3, well up into the embayment where the bed is wet.

\section{'MIRROR' CREVASSE SIGNATURES}

Finally, we report a curious group of crevasse signatures (one is shown in Fig. 2d) that appear to show a low-angle reflector 'mirrored' on both sides of the basal echo. The symmetry of these two branches is striking at first glance, but close inspection shows that it is not perfect. Both reflectors have the same phase as the basal echo, but the lower echo is generally $\sim 10 \mathrm{~dB}$ weaker than the upper echo, which, in turn, is $\sim 20 \mathrm{~dB}$ weaker than the bed amplitude. Six of these mirrored crevasse signatures occur in a closely spaced group of our profiles on the south side of the embayment (group 2, Fig. 1). They are present in both longitudinal and transverse profiles, the latter sometimes completed in alternate directions, so the features are in approximately the same location relative to the grounding line regardless of the direction of travel. The pattern of these double crevasse echoes forms a smooth arc seen in map view with the meeting point of the two branches located just down-flow from where sediment emerges from beneath the ice (Horgan and others, 2013a,b) and with the diverging portions of the echoes always opening in the up-flow direction, away from the subglacial embayment (Fig. 4). At this location, reflection seismics image a water-filled channel emerging from beneath the ice (Horgan and others, 2013a,b).

The difficulty in conceptualizing the geometry producing this 'mirrored' echo pattern is that energy arriving at travel times shorter than the basal echo is detected at the same location as energy arriving from a longer travel path and has the same phase. As the radar system traverses the ice-shelf surface, the rough symmetry is preserved until energy arrives along both paths at approximately the same time as the basal echo. Based on our simulations, it is impossible for energy returning from a single object to arrive along paths that are both longer and shorter than from the nadir by roughly equal amounts, and to maintain this symmetry as

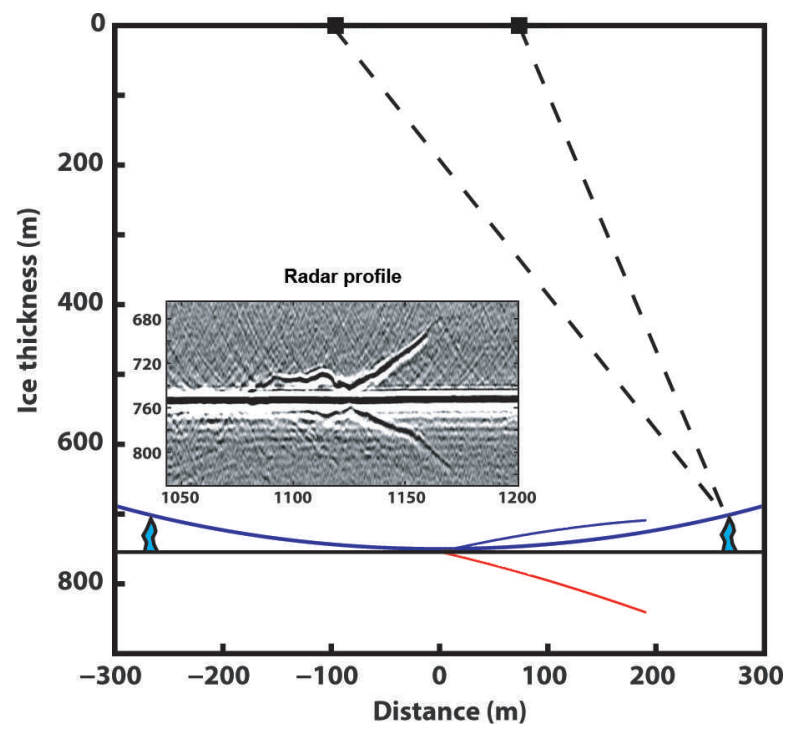

Fig. 5. Modeled ray paths for echoes arriving from two similar crevasses, fore and aft of the radar transmitter and receiver. Energy returned from points anywhere along the ellipse with the transmitter and receiver as foci is coincident in time with the nadir echo. As the radar moves to the right, echoes from the forward crevasse arrive at earlier times (blue line) while those from the crevasse at the rear arrive later (red line). Inset shows the radargram from a portion of the along-flow profile, third from left in Figure 4.

the radar system moves along a line approaching or moving away from the object.

A simple geometry that satisfies these observations (giving the correct timing, amplitude and phase) is reflections from two similar objects near the bed, separated by a distance larger than the transmitter/receiver dimension. Figure 5 shows our proposed geometric arrangement, wherein echoes are produced by a pair of basal crevasses, such as those that might be located on each side of a channel incised into the sediment below the ice. Stresses produced in the ice as this channel fills and empties could produce the crevassing. When the radar is midway between the crevassed margins, echoes from energy scattered near the top of crevasses both fore and aft of the radar arrive at approximately the same time as the brighter nadir bed echo (points with equal arrival times form an ellipse with the transmitter and receiver at the foci). As the radar approaches the more forward crevasse, arrival times from it decrease, while they increase for echoes from behind, producing echo patterns in the profile with both increasing and decreasing arrival times, as well as one from the nadir reflection at a constant distance. Echo amplitudes are larger from the forward target, dimmer from behind, and brightest from the nadir; the phase is the same for all, matching conditions of the observed profiles. One of the longitudinal profiles (Fig. 5, inset) shows the longest and most complex double-echo pattern and crosses the channel at a more oblique angle than the transverse profiles (Fig. 4). The flatter portion of the echo traces, just above and below the nadir, result from energy arriving from off-axis just before and after the echo from directly below, as the radar passes obliquely over the central portion of the channel.

We note that the complete echo signature expected from two crevasses in the geometry suggested is two hyperbolae with the limbs from the fore and aft branches crossing in an ' $X$ ' pattern with the crossing point approximately coincident with the nadir basal echo. The mirrored pattern we show in 
Figures $2 \mathrm{~d}$ and 5 is then just one side of this ' $X$ ' We observe the other side of the ' $X$ ' in some, but not all, profiles.

We can use this ellipse geometry, together with the height of the crevasses, to estimate the width of the channel in the locations where it is crossed, and find that it varies between about 600 and $750 \mathrm{~m}$. The approximate trace of the channel in map view from the echo locations in group 2 is depicted as a white dashed arrow in Figure 1. This agrees well with the estimate of $1 \mathrm{~km}$ width and the approximate channel location from seismic observations that imaged a water-filled incised channel in two crossed profiles (Horgan and others, 2013a). We note that, due to the likely presence of a thin layer of brackish water near grounding and the well-mixed subglacial tidal estuary in this location, there is no strong radar reflectivity contrast as we transition from grounded to floating ice. Thus, this channel would be undetectable by RES if we relied on changes in basal reflectivity alone. We note that other explanations may be possible for the mirror crevasses, but echoes from crevasses at both margins of a channel that has been imaged in the seismic profiles seem to best fit the observations.

\section{CONCLUSIONS}

Overall, our results indicate that basal crevasses offer a rich dataset for diagnosing stress state and salient processes that occur across grounding zones. Carefully interpreted, they can yield much useful information. We point out, however, that special care is needed when interpreting returns from an impulse system, such as ours, with a wide antenna beam pattern towed in the end-to-end configuration. Off-nadir targets can produce strong echoes that are difficult to interpret, especially when energy is reflected from a very bright, nearly planar basal reflector, such as sea water. As we have shown, this produces a phase reversal, and subsequent reflections can mimic returns interpreted as subglacial. At the same time, the off-nadir echoes can be exploited in some circumstances to provide an illuminating view of the world below.

\section{ACKNOWLEDGEMENTS}

We thank our colleagues on the WISSARD geophysics field team for assistance in Antarctica, particularly Benjamin Peterson and Huw Horgan. This work was supported by grants from the US National Science Foundation ANT0838854 and ANT-0838855 to St Olaf College as part of the American Recovery and Reinvestment Act of 2009. The US National Snow and Ice Data Centre (NSIDC) provided dInSAR data. GPS base station data were obtained from The University Navstar Consortium (UNAVCO) and the Scripps Orbit and Permanent Army Center (SOPAC). We thank Eric Rignot for digitization of the grounding line and maximum extent of the flexure zone in dInSAR data. We thank Hugh Corr, Scientific Editor, David Vaughan and an anonymous reviewer for helpful comments. Logistical support was provided by Raytheon Polar Services, Kenn Borek Air and the New York Air National Guard.

\section{REFERENCES}

Alley RB, Blankenship DD, Bentley CR and Rooney ST (1987) Till beneath Ice Stream B. 3. Till deformation: evidence and implications. J. Geophys. Res., 92(B9), 8921-8929 (doi: 10.1029/JB092iB09p08921)
Alley RB, Anandakrishnan S, Dupont TK, Parizek BR and Pollard D (2007) Effect of sedimentation on ice-sheet grounding-line stability. Science, 315(5820), 1838-1841 (doi: 10.1126/science. 1138396)

Anandakrishnan S, Catania GA, Alley RB and Horgan HJ (2007) Discovery of till deposition at the grounding line of Whillans Ice Stream. Science, 315(5820), 1835-1838 (doi: 10.1126/ science.1138393)

Arcone SA (1995) Numerical studies of the radiation patterns of resistively loaded dipoles. J. Appl. Geophys., 33(1-3), 39-52 (doi: 10.1016/0926-9851(95)90028-4)

Bindschadler R, Vaughan DG and Vornberger P (2011) Variability of basal melt beneath the Pine Island Glacier ice shelf, West Antarctica. J. Glaciol., 57(204), 581-595 (doi: 10.3189/ 002214311797409802)

Blankenship DD, Bentley CR, Rooney ST and Alley RB (1987) Till beneath Ice Stream B. 1. Properties derived from seismic travel times. J. Geophys. Res., 92(B9), 8903-8911 (doi: 10.1029/ JB092iB09p08903)

Brunt KM, Fricker HA, Padman L, Scambos TA and O'Neel S (2010) Mapping the grounding zone of Ross Ice Shelf, Antarctica, using ICESat laser altimetry. Ann. Glaciol., 51(55), 71-79 (doi: 10.3189/172756410791392790)

Carter SP and Fricker HA (2012) The supply of subglacial meltwater to the grounding line of the Siple Coast, West Antarctica. Ann. Glaciol., 53(60 Pt 2), 267-280 (doi: 10.3189/ 2012AoG60A119)

Catania GA, Conway H, Raymond CF and Scambos TA (2006) Evidence for floatation or near floatation in the mouth of Kamb Ice Stream, West Antarctica, prior to stagnation. J. Geophys. Res., 111(F1), F01005 (doi: 10.1029/2005JF000355)

Catania GA, Hulbe CL and Conway HB (2010) Grounding-line basal melt rates determined using radar-derived internal stratigraphy. J. Glaciol., 56(197), 545-554 (doi: 10.3189/ 002214310792447842)

Christianson K, Jacobel RW, Horgan HJ, Anandakrishnan S and Alley RB (2012) Subglacial Lake Whillans - ice-penetrating radar and GPS observations of a shallow active reservoir beneath a West Antarctic ice stream. Earth Planet. Sci. Lett., 331-332, 237-245 (doi: 10.1016/j.epsl.2012.03.013)

Christianson K and 8 others (2013) Ice sheet grounding zone stabilization due to till compaction. Geophys. Res. Lett., 40(20), 5406-5411 (doi: 10.1002/2013GL057447)

Fricker HA and Scambos T (2009) Connected subglacial lake activity on lower Mercer and Whillans Ice Streams, West Antarctica, 2003-2008. J. Glaciol., 55(190), 303-315 (doi: 10.3189/002214309788608813)

Fricker HA, Scambos T, Bindschadler R and Padman L (2007) An active subglacial water system in West Antarctica mapped from space. Science, 315(5818), 1544-1548 (doi: 10.1126/ science.1136897)

Fricker HA, Coleman R, Padman L, Scambos TA, Bohlander J and Brunt KM (2009) Mapping the grounding zone of the Amery Ice Shelf, East Antarctica using InSAR, MODIS and ICESat. Antarct. Sci., 21(5), 515-532 (doi: 10.1017/S095410200999023X)

Horgan HJ and 7 others (2012) Subglacial Lake Whillans - seismic observations of a shallow active reservoir beneath a West Antarctic ice stream. Earth Planet. Sci. Lett., 331-332, 201-209 (doi: 10.1016/j.epsl.2012.02.023)

Horgan HJ and 7 others (2013a) Estuaries beneath ice sheets. Geology, 41(11), 1159-1162 (doi: 10.1130/G34654.1)

Horgan HJ, Christianson K, Jacobel RW, Anandakrishnan S and Alley RB (2013b) Sediment deposition at the modern grounding zone of Whillans Ice Stream, West Antarctica. Geophys. Res. Lett., 40(15), 3934-3939 (doi: 10.1002/grl.50712)

Jacobel RW, Scambos TA, Nereson NA and Raymond CF (2000) Changes in the margin of Ice Stream C, Antarctica. J. Glaciol., 46(152), 102-110 (doi: 10.3189/172756500781833485)

Jezek KC (1984) A modified theory of bottom crevasses used as a means for measuring the buttressing effect of ice shelves on 
inland ice sheets. J. Geophys. Res., 89(B3), 1925-1931 (doi: 10.1029/JB089iB03p01925)

Luckman A, Jansen D, Kulessa B, King EC, Sammonds P and Benn DI (2012) Basal crevasses in Larsen C Ice Shelf and implications for their global abundance. Cryosphere, 6(1), 113-123 (doi: 10.5194/tc-6-113-2012)

MacGregor JA, Anandakrishnan S, Catania GA and Winebrenner DP (2011) The grounding zone of the Ross Ice Shelf, West Antarctica, from ice-penetrating radar. J. Glaciol., 57(205), 917928 (doi: 10.3189/002214311798043780)

Matsuoka K, Gades A, Conway H, Catania G and Raymond C (2009) Radar signatures beneath a surface topographic lineation near the outlet of Kamb Ice Stream and Engelhardt Ice Ridge, West Antarctica. Ann. Glaciol., 50(51), 98-104 (doi: 10.3189/ 172756409789097595)

McGrath D, Steffen K, Rajaram H, Scambos T, Abdalati W and Rignot E (2012) Basal crevasses on the Larsen C Ice Shelf, Antarctica: implications for meltwater ponding and hydrofracture. Geophys. Res. Lett., 39(16), L16504 (doi: 10.1029/ 2012GL052413)

Parizek BR and 10 others (2013) Dynamic (in)stability of Thwaites Glacier, West Antarctica. J. Geophys. Res., 118(F2), 638-655 (doi: 10.1002/jgrf.20044)
Peters ME, Blankenship DD and Morse DL (2005) Analysis techniques for coherent airborne radar sounding: application to West Antarctic ice streams. J. Geophys. Res., 110(B6), B06303 (doi: 10.1029/2004JB003222)

Rignot E, Velicogna I, Van den Broeke MR, Monaghan A and Lenaerts J (2011a) Acceleration of the contribution of the Greenland and Antarctic ice sheets to sea level rise. Geophys. Res. Lett., 38(5), L05503 (doi: 10.1029/2011GL046583)

Rignot E, Mouginot J and Scheuchl B (2011b) Antarctic grounding line mapping from differential satellite radar interferometry. Geophys. Res. Lett., 38(10), L10504 (doi: 10.1029/ 2011GL047109)

Vaughan DG and 8 others (2012) Subglacial melt channels and fracture in the floating part of Pine Island Glacier, Antarctica. J. Geophys. Res., 117(F3), F03012 (doi: 10.1029/ 2012JF002360)

Welch BC and Jacobel RW (2003) Analysis of deep-penetrating radar surveys of West Antarctica, US-ITASE 2001. Geophys. Res. Lett., 30(8), 1444 (doi: 10.1029/2003GL017210)

Welch BC, Jacobel RW and Arcone SA (2009) First results from radar profiles collected along the US-ITASE traverse from Taylor Dome to South Pole (2006-2008). Ann. Glaciol., 50(51), 35-41 (doi: 10.3189/172756409789097496) 